\title{
Distinct and Dynamic Auxin Activities During Reproductive Development
}

\author{
Eva Sundberg ${ }^{1}$ and Lars Østergaard ${ }^{2}$ \\ ${ }^{1}$ Uppsala BioCenter, Department of Plant Biology and Forest Genetics, Swedish University \\ of Agricultural Sciences, S-750 07 Uppsala, Sweden \\ ${ }^{2}$ Crop Genetics Department, John Innes Centre, Colney Lane, Norwich NR4 7UH, United Kingdom \\ Correspondence: eva.sundberg@vbsg.slu.se
}

Flowering plants have evolved sophisticated and complicated reproductive structures to ensure optimal conditions for the next generation. Successful reproduction relies on careful timing and coordination of tissue development, which requires constant communication between these tissues. Work on flower and fruit development over the last decade places the phytohormone auxin in a key role as a master of patterning and tissue specification of reproductive organs. Although many questions still remain, it is now clear that auxin mediates its function in flowers and fruits through an integrated process of biosynthesis, transport, and signaling, as well as interaction with other hormonal pathways. In addition, the knowledge obtained so far about auxin function already allows researchers to develop tools for crop improvement and precision agriculture.

Flower and fruit development requires a preF cise patterning of organs and tissues, which also have to be coordinated for the successful fulfillment of the tasks inherited. The plant hormone auxin has received a lot of attention for its prominent role in organ positioning as well as in organ polarity formation and differentiation, and flowers and fruits make no exception to the dependency on auxin in these aspects. In addition, auxin appears to participate in the coordination of processes within, as well as between, floral organs, aiding for example in successful fertilization. In this article, we focus on the role of auxin in the establishment of the flower, and specifically in the development and dehiscence of the reproductive floral organs.

\section{AUXIN MARKS THE FLORAL MERISTEM INITIATION SITES AND IS REQUIRED FOR FLORAL ORGAN DEVELOPMENT}

A constant relocalization of PIN auxin efflux facilitator proteins and auxin influx carriers participates in the generation of distinct local auxin maxima in the peripheral zone of the inflorescence meristem (Heisler et al. 2005). In Arabidopsis these sites are formed in a spiral arrangement, and are required for floral meristem formation, just as local auxin maxima sites

Editors: Mark Estelle, Dolf Weijers, Karin Ljung, and Ottoline Leyser

Additional Perspectives on Auxin Signaling available at www.cshperspectives.org

Copyright (C 2009 Cold Spring Harbor Laboratory Press; all rights reserved; doi: 10.1101/cshperspect.a001628

Cite this article as Cold Spring Harb Perspect Biol 2009;1:a001628 
are used for leaf primordia initiation in the vegetative apical meristem (Heisler et al. 2005; Okada et al. 1991; Vernoux et al. 2000; Reinhardt et al. 2000, 2003). Auxin also acts as a local morphogenic trigger of floral organ primordia initiation in four concentric whorls around the central floral meristem (Nemhauser et al. 2000; Tobena-Santamaria et al. 2002; Cheng et al. 2006). Organ boundaries on the other hand, have been suggested to require low auxin levels, allowing for organ boundary gene activity and growth repression (Heisler et al. 2005). The identity of initiated floral organ primordia is determined by so called homeotic genes (Coen 1992; Weigel and Meyerowitz 1994), and recently a direct molecular link between the floral homeotic gene SEPALLATA3 (SEP3) and auxin response pathways, including several AUXIN RESPONSE FACTOR (ARF) genes, have been made (Kaufmann et al. 2009), suggesting that auxin regulates floral organ growth and differentiation, partially downstream of the organ identity genes. As for the majority of lateral organs, auxin also marks the apical end of the floral organ primordia (Benkova et al. 2003), and determines the venation pattern.

\section{AUXIN REGULATES BOTH EARLY AND LATE STAGES OF STAMEN AND POLLEN DEVELOPMENT}

\section{Stamen and Pollen Development}

Stamen primordia constitute the third whorl of floral organs and appear after sepal and petal primordia initiation but before the gynoecium primordia. Soon after appearance, the stamen primordia differentiate into the anther and filament compartments. The filament consists of vascular tissue for water and nutrient supply, whereas the anther contains the tissues responsible for the production and subsequent release of pollen grains. Because anther and pollen development has been extensively reviewed elsewhere (Goldberg et al. 1993; McCormick 2004; Ma 2005; Wilson and Zhang 2009), the major steps are only briefly presented here (Fig. 1). The first phase of anther morphogenesis involves the formation of the connective tissue, the predifferentiation of sites for pollen release, and the development of anther locules lined internally with a nutritious cell layer called the tapetum, which encloses diploid pollen mother cells. This phase ends with meiosis of mother cells, resulting in tetrads of haploid cells together enclosed by a thick callose wall. This wall will, in phase two, be degraded by the action of callase, produced by the tapetum cell layer, which results in the release of free haploid microspores from the tetrads. Subsequently, asymmetric mitosis transforms microspores to pollen grains, consisting of a larger vegetative cell that engulfs a smaller generative cell. In parallel, preparations for pollen release take place, resulting in connective tissue destruction, endothecium cell wall lignification, and stamen filament elongation, allowing the anther to reach the stigma. After partial dehydration, mature pollen grains are released through breakage of stomium cells. The pollen grain rehydrates on the stigma, allowing the vegetative cell to form the pollen tube by tip growth, and this is the stage when the generative cell of most species undergoes mitosis to form two sperm cells. The nuclei of the vegetative cell and the two sperm cells will enter the tube, and when the sperm cells are released into the embryo sac, pollen development is completed.

\section{Auxin in Early Stamen Development (Morphogenesis, Phase 1)}

Early during floral development (stage 9) (Bowman et al. 1994), the auxin biosynthesis genes YUC2 and YUC6 are expressed in the thecas (carrying the reproductive tissues, before differentiation and subsequently in pollen mother cells), the tapetum, the endothecium, and procambium, and the expression stays on in most of these tissues through stage 11 (Cecchetti et al. 2008). In these cell layers, members of the TIR/ABF auxin receptor gene family and the DR5 auxin response constructs are activated, but at a slightly later stage (Fig. 1) (Cecchetti et al. 2008; Feng et al. 2006). Because polar auxin transport (PAT) restrictions, inflicted by the auxin transport inhibitor NPA, do not affect auxin responses during early stages of anther 


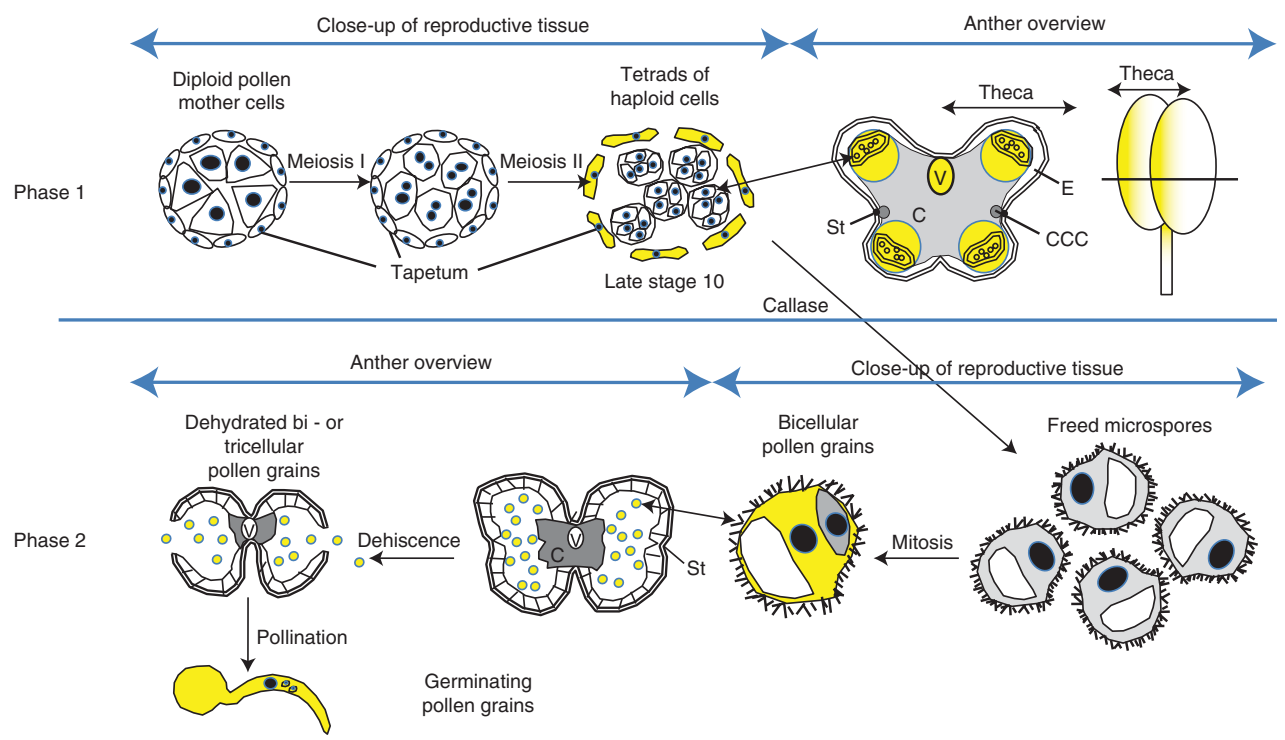

Figure 1. Schematic picture of pollen and anther development. Diploid pollen mother cells surrounded by a tapetum layer goes through meiosis in phase 1. Auxin responses (yellow) are detected in the tapetum layer, the theca and the vasculature $(\mathrm{V})$ from late stage 10. Callase released from the tapetum subsequently frees the microspore from the tetrads, and during phase 2, the microspore goes through mitosis. During these stages, auxin responses are detected in the pollen grains. The anthers dehisce and release the dehydrated pollen grains. St, stomium; CCC, circular cell cluster; V, vascular bundle; C, connective tissue; E, endothecium.

morphogenesis, it has been suggested that early anther development is mainly dependent on local auxin biosynthesis (Cecchetti et al. 2008). The role of auxin during these early stages has not yet been determined, but it is likely that auxin participates in the differentiation, activity, and/or fate of, for example, the tapetum layer, which plays critical roles in providing enzymes for microspore release, material for pollen wall formation, and nutrients for pollen maturation (Esau 1977; Pacini et al. 1985). It has also been suggested that the tapetum layer may supply the developing pollen grains with indole acetic acid (IAA) (Aloni et al. 2006) and reduced auxin levels in the tapetum results in decreased pollen embryogenesis (Yang et al. 1997).

\section{Auxin Is Required for Stamen Filament Elongation, Pollen Maturation, and Anther Dehiscence (Phase 2)}

Mutant analysis revealed that auxin is required also for a number of later events during stamen development. First, yuc2 yuc6 lines, auxin receptor mutants ( $t$ ir $a f b$ ), and lines with reduced auxin response gene activity (arf6 arfo mutants and lines overexpressing miR167) fail to elongate stamen filaments at anthesis (Cheng et al. 2006; Cecchetti et al. 2008; Nagpal et al. 2005; $\mathrm{Ru}$ et al. 2006; Wu et al. 2006), suggesting that auxin is required for this process. In accordance, YUC2 and DR5 reporter lines are expressed apically in the filament (Cheng et al. 2006; Cecchetti et al. 2008). Furthermore, PAT appears important for later stages of filament elongation, as both NPA-treated flowers and flowers of the $m d r 1$ pgp1 transport double mutant have short filaments (Cecchetti et al. 2008; Noh et al. 2001). Auxin transport from the filament to the anthers may also affect some of the later stages of pollen development. Feng et al. (2006) reduced the IAA levels only in the stamen filament by expressing the bacterial iaaL gene from a filament-specific promoter, $P M 5-K$. The iaaL gene product induces the conjugation of free IAA to inactive IAA-lysine. This resulted, as expected, in defected anther filament elongation, and also in a reduction 
of DR5:GUS anther expression and pollen viability. Tapetum development appeared normal, whereas pollen mitosis was affected. This suggests that auxin needs to be transported through the stamen filament not only for induction of filament elongation but also for normal pollen development (Feng et al. 2006). However, reduced auxin biosynthesis during pollen development results in a complete loss of pollen formation, suggesting that both biosynthesis and transport is required (Cheng et al. 2006).

Second, auxin affects the timing of anther dehiscence, which occurs precociously in the tir abf mutants (Cecchetti et al. 2008) and becomes delayed by enhanced auxin sensitivity (Cecchetti et al. 2004), suggesting that auxin responses normally prevent premature dehiscence. The dehiscence program is initiated after tetrad formation in wild type and results in the sequential destruction of specific anther cell types, and is coordinated temporally with the pollen differentiation process. Anther dehiscence includes degeneration of the tapetum, thickening of the endothecial cell walls, merging of the two pollen sacs into a single locule, breakdown of connective tissue, and finally rupture at the stomium site (Fig. 1). The endothelium cell wall lignification and stomium disruption occurred earlier in the mutant lines and represents tissues in which DR5 constructs, as well as auxin biosynthesis and response genes are expressed (Cecchetti et al. 2008). Furthermore, auxin also appears to prevent precocious pollen maturation; pollen grains of the tir afb multiple mutants initiate mitosis and germinate earlier than wild-type pollen, and DR5 reporter lines appear to be active both during meiosis and mitosis (Cecchetti et al. 2008; Feng et al. 2006). Taken together, these results suggest that auxin coordinates the timing of anther dehiscence and pollen maturation (Cecchetti et al. 2008).

Auxin function in anther and pollen development is likely to occur via interactions with other hormonal pathways. Jasmonic acid (JA) is involved in the final stages of anther dehiscence, pollen maturation, and in filament elongation (Sanders et al. 2000; Ishiguro et al.
2001; Nagpal et al. 2005). Based on the observation that arf6 arf8 double mutants have dramatically reduced JA levels in developing flowers, and that the indehiscent arf6 arf8 stamens can be rescued by JA treatment, it was suggested that auxin acts on JA during anther and pollen maturation (Cecchetti et al. 2008; Nagpal et al. 2005). The factors that are involved in this interaction have not yet been identified. However, because both auxin and JA signaling involves protein degradation via the 26S proteasome (Santner and Estelle 2009), it is plausible that protein stability plays a central role.

\section{AUXIN PLAY FUNDAMENTAL ROLES IN POLARITY AND TISSUE DIFFERENTIATION DURING GYNOECIUM DEVELOPMENT}

\section{Gynoecium Development}

The angiosperm female structure, the gynoecium, which develops in the central organ whorl, protects ovules, selects male gametophytes, and aids pollen tube growth toward the ovules. After fertilization, the gynoecium develops into a fruit that initially protects and subsequently disperses the seeds. The developmental processes of the gynoecium have been reviewed elsewhere (Balanza et al. 2006; Østergaard 2009; Sundberg and Ferrandíz 2009) and are therefore only briefly summarized here. The Arabidopsis gynoecium (Fig. 2) develops from two congenitally fused carpels, which have evolved from ancestral leaflike structures (Goethe 1790; Pelaz et al. 2001; Castillejo et al. 2005; Honma and Goto 2001; Ditta et al. 2004). The gynoecium primordium grows into a hollow cylinder and the fused carpel margins develop two meristematic ridges, which laterally give rise to placentae and ovules (Esau 1977). The meristematic ridge also produces a bulge that fuses centrally to form the septum, harboring the transmitting tract used by growing pollen tubes. An apical-basal patterning also occurs, resulting in apical gynoecia enclosure, followed by the development of style and stigma. At the base, a gynophore connecting the centrally localized ovary to the 


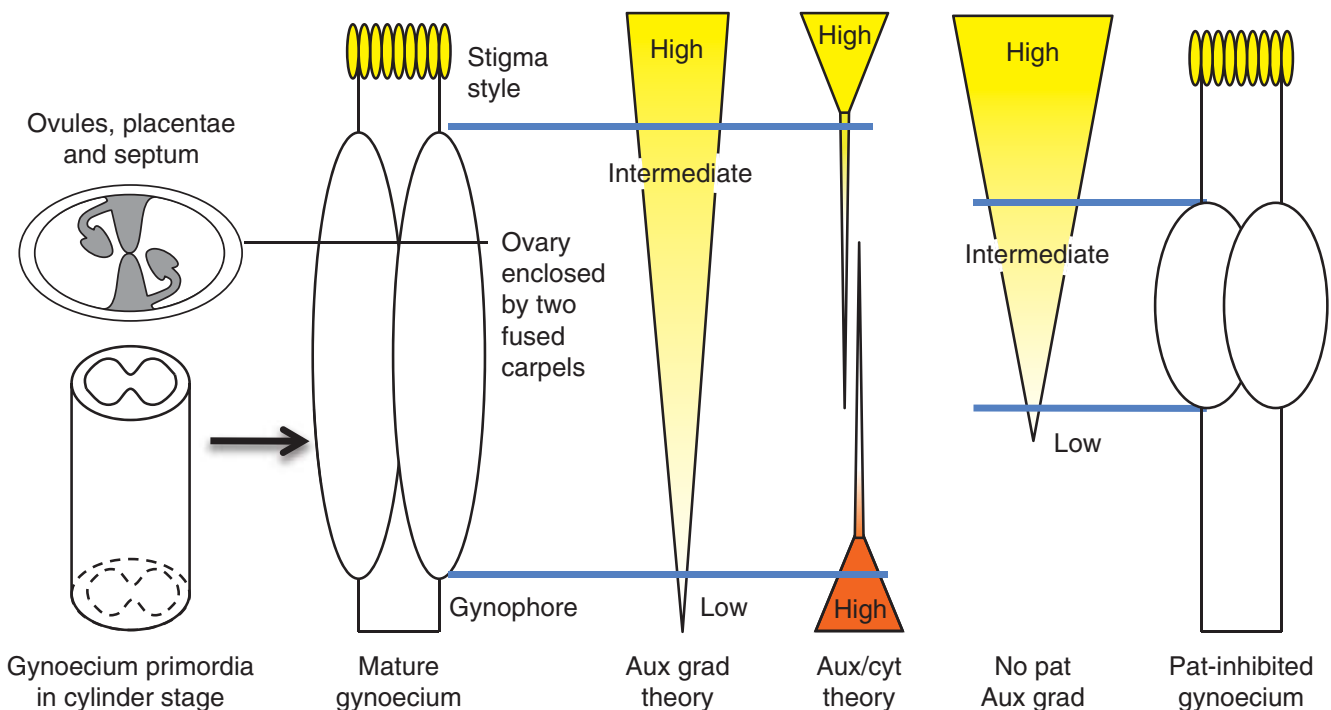

Figure 2. Gynoecium morphology and the auxin gradient theory. The gynoecium promordia develops as an open cylinder that fuses apically to form the style and stigma, and internally to form the septum (gray) and placentae with ovules (gray). The apical-basal patterning has been suggested to depend on an auxin gradient (Nemhauser et al. 2000), and according to the proposed model, high auxin (yellow) apically results in style and stigma proliferation, whereas intermediate auxin level is required for ovary formation, and low level for gynophore formation. Reduction in PAT would result in trapping of apically produced auxin and thus in a steeper auxin gradient, resulting in boundary shifts. An alternative model proposed by Østergaard (2009) suggests that the ovary is formed in a low auxin (yellow) and cytokinin (orange) region, whereas high auxin induces style and stigma, and high cytokinin the gynophore.

flower develops. At anthesis, all reproductive tissues have developed and those required for fruit maturation and dehiscence are already specified (Bowman et al. 1999; Alvarez and Smyth, 2002; Roeder and Yanofsky, 2005).

\section{Auxin in Apical-Basal Gynoecium Pattern Formation}

Auxin has been suggested to act as a major morphogen-directing apical-basal patterning of the gynoecium. Mutant lines defective in PAT or the activity of ETT/ARF3 and ARF5 display enlarged apical and basal regions concomitantly with strongly reduced ovaries (Okada et al. 1991; Bennett et al. 1995; Przemeck et al. 1996; Sessions et al. 1997; Sessions and Zambryski 1995). Thus, Nemhauser et al. (2000) proposed that the apical-basal patterning is established by a suggested auxin gradient spanning the gynoecia primordia (Fig. 2). According to their model, high auxin levels in the apical region would promote style and stigma development, whereas intermediate and low levels would specify ovary and gynophore, respectively. In accordance, proposed regulators of auxin biosynthesis (STYLISH [STY]/SHORT INTERNODES [SHI], NGATHA [NGA] genes) and their downstream targets (e.g., the auxin biosynthesis genes YUC2 and YUC4) are all expressed in the apical end of the developing gynoecia (Kuusk et al. 2006; Sohlberg et al. 2006; Trigueros et al. 2009; Alvarez et al. 2009; Cheng et al. 2006). Reduced PAT would thus result in trapping auxin apically, causing shifts in the boundaries between the different tissues (Fig. 2) (Nemhauser et al. 2000). The bHLH transcription factors SPATULA (SPT)/HECATE (HEC) have been suggested to respond to high auxin levels, or to participate in the regulation of PAT, thereby directing stigma, style, and transmitting tract differentiation (Alvarez and Smyth 1999; Heisler et al. 2001; Gremski et al. 2007). ETT/ARF3 represses the SPT/HEC activity 
in the ovary region, and may, by responding to intermediate auxin levels, establish the ovary size (Sessions and Zambryski 1995; Sessionset al. 1997; Heisler et al. 2001; Pekker et al. 2005). Although the proposed auxin gradient can be used to build a model for apical-basal patterning, no auxin level measurements along the length of the gynoecia has yet been reported, which can support the existence of such a gradient. Auxin response reporters, just as the auxin biosynthesis regulators, are expressed at high levels apically, whereas no expression is detected in the middle ovary (Aloni et al. 2006; Benková et al. 2003), suggesting the existence of only two separate auxin level domains. Based on these facts, the auxin gradient theory was complemented by suggesting the existence of a reversed cytokinin gradient, with a concentration maximum at the base of the gynoecium, resulting in three distinct territories; high auxin/low cytokinin apically, low auxin/low cytokinin in the middle, and low auxin/high cytokinin basally (Fig. 2) (Østergaard 2009). Future studies will shed light on the current gradient models.

Internally, Transmitting Tract and Ovule Development Requires Auxin Activity

Although less is known about the role of auxin in the regulation of tissues derived from the meristematic carpel margins, it is clear that auxin is required for, for example, transmitting tract morphogenesis and ovule development. The development of the transmitting tract, which spans the length of the gynoecium and facilitates pollen tube tip growth by secreting a polysaccharide rich extracellular matrix (Lennon et al. 1998; Wang et al. 1996; Crawford et al. 2007), is largely dependent on the activity of genes connected to auxin production or responses such as the HEC, SPT, SHI/STY, and ETT/ARF3 genes (Gremski et al. 2007; Alvarez and Smyth 2002; Heisler et al. 2001; Kuusk et al. 2006; Sohlberg et al. 2006; Crawford and Yanofsky 2008). Furthermore, ARF6 and ARF8, expressed within the stigma, style, and transmitting tract, have been suggested to regulate the production of some component necessary for pollen tube germination or growth (Wu et al. 2006).
Auxin responses also peak in the apical end of developing ovules (the nucellus tip) and integument primordia (forming the outer ovule layer), where it coincides with the expression of auxin biosynthesis activators, such as STY1 (Benkova et al. 2003; Kuusk et al. 2002). In addition, PIN1 is expressed in the ovule epidermis and integuments in a polarized manner, supporting an apical auxin peak formation (Benkova et al. 2003). Furthermore, in ovule integument mutants, the PIN1, TIR1, AFB1, and $A F B 3$ genes were all down-regulated, demonstrating a close link between integument formation and auxin (Skinner and Gasser 2009). Development of the female gametophyte of angiosperms is initiated by formation of a single cell (syncitium) with eight nuclei that are distributed to individual compartments and eventually partitioned into seven individual cells. It was recently found that the precise distribution of these nuclei depends on an asymmetric distribution of auxin (Pagnussat et al. 2009). The gradient is formed by local auxin biosynthesis and this exciting finding adds an extra dimension to the way auxin regulates cellular processes.

In conclusion, the events that prepare the individual tissues of the gynoecium for fertilization and fruit growth all rely on auxin dynamics to ensure proper patterning and tissue specification.

\section{FERTILIZATION AND POSTFERTILIZATION PROCESSES ARE DEPENDENT ON AUXIN SIGNALING}

\section{Pollination}

The landing of pollen on a compatible stigma marks the beginning of pollination and fertilization. The pollen will then adhere, hydrate, and germinate to produce the pollen tube, a structure specialized in the delivery of the sperm cells to the ovule. In a genome-wide transcriptomic approach using stigmatic tissue from rice, it was found that several auxinsignaling genes were overrepresented in the stigma gene set (Li et al. 2007). In agreement with this, a very detailed study of auxin distribution in the stigma and style of Nicotiana 
tabacum suggests that auxin distribution plays an important role in the pollination process (Chen and Zhao 2008). In this study, high levels of free auxin in stigmas and styles during pollen germination and pollen-tube growth were detected by immunolocalization. The auxin levels (immuno detection) and response (DR5::GUS) increased in the part of the transmitting tract where pollen tubes would enter and then rapidly declined in the part where pollen tubes had penetrated, suggesting that auxin is important for growth of the pollen tube tip.

\section{Seed-to-Pod Communication}

In 1936, Gustafson discovered that application of synthetic auxins to emasculated flowers of several different plant species resulted in fruit development in the absence of fertilization, a process known as parthenocarpy. This experiment established the initial linkage between fruit initiation and plant-growth regulators, and presently auxin, gibberellins, and cytokinin are recognized to have the ability to induce fruit setting and fruit development in a wide range of plant species (Gillaspy et al. 1993; Gustafson 1936; King 1947; Wittwer et al. 1957; Ozga et al. 2002; Ozga et al. 2003; Srinivasan et al. 1996; Vivian-Smith et al. 1999).

Although these results indicate that fruit initiation is coordinated by phytohormone biosynthesis during seed development, it is only now that molecular data to support this idea are beginning to emerge. In a facultative parthenocarpic Arabidopsis mutant, dramatically reduced IAA levels were found in unpollinated versus pollinated fruits, even though the unpollinated grew to almost the same length (Fuentes and Østergaard, unpubl.). A detailed study showed that the only difference between these fruits is the presence or absence of seeds, suggesting that the seeds are the main source of auxin (Fuentes et al., submitted). In another example, it was recently reported that gibberellin (GA) biosynthesis genes are upregulated on pollination of pea fruits and that this regulation depends on the presence of seeds (Ozga et al. 2009). However, the auxin
4-chloro-IAA (4-Cl-IAA) was found to mimic this effect in the absence of fertilization, thereby directly confirming previous results that auxin and gibberellin pathways interact to mediate fruit initiation (Sastry and Muir 1963; Koshioka et al. 1994). Moreover, Ozga et al. (2009) also found that GA biosynthesis was induced by applying 4-Cl-IAA to deseeded pericarp, supporting the hypothesis that auxin is synthesized in the seed on fertilization and transported to the pericarp to induce GA-mediated fruit growth.

Central to GA signaling are DELLAs, nuclear proteins characterized by a conserved DELLAmotif in their amino-terminal domain (Peng et al. 1997; Silverstone et al. 1998). According to the "relief of restraint" model (Harberd 2003), DELLA proteins act as growth repressors, and GA-mediated DELLA degradation is required to overcome this restraint. The crucial role of DELLA proteins in GA signaling is well understood and their role in fruit development has recently been identified by Marti et al. (2007), Dorcey et al. (2009) and Fuentes et al. (submitted), who showed that lack of DELLA proteins results in parthenocarpic fruit development.

Based on the molecular data described previously, a model is emerging for fruit initiation in which auxin is synthesized in the ovules on fertilization and then transported to the pericarp, where it induces GA biosynthesis. In turn, the newly synthesized GA will lead to DELLA degradation and thereby relief of growth repression to allow fruit elongation (Fig. 3). This description is highly simplified, and there are most certainly additional layers of regulation. For example, it has been shown that a threshold level of GA in the gynoecium is required to initiate the auxin biosynthesis, providing a feedback circuit (Vivian-Smith and Koltunow 1999). Further elucidation of the hormonal interactions during fruit initiation will provide exciting insight into the setup of fruit development.

\section{Parthenocarpy in Crops}

There are major advantages of parthenocarpy in crops. For example, fruit seedlessness is advantageous for fruit processing (e.g., tomato 
E. Sundberg and L. Østergaard
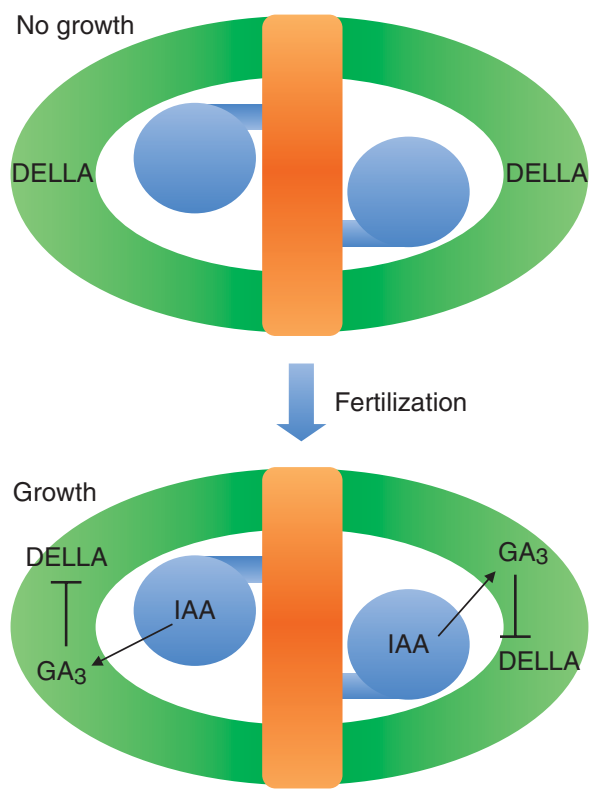

Figure 3. Model for hormonal activities on fertilization. The figure shows schematic cross sections of an Arabidopsis gynoecium. Before fertilization (top), DELLA proteins repress growth and elongation of the ovary. On fertilization (bottom), auxin (IAA) is produced in the ovules, inducing $\mathrm{GA}_{3}$ production in the valves. $\mathrm{GA}_{3}$ then mediates DELLA degradation and fruit growth.

paste), it can improve fruit quality (e.g., eggplant), or seedlessness can simply be a feature appreciated by consumers (e.g., grape and melon). Moreover, in parthenocarpic plants, fruit set and production is less affected by environmental factors adverse for pollination and fertilization.

Parthenocarpy can either be elicited by artificial means or via genetic modifications. In agriculture, auxin and gibberellin are the most common phytohormones used to trigger artificial parthenocarpy. Genetic parthenocarpy can be either facultative or obligate. In facultative parthenocarpy, the fruits are seedless only when grown under conditions adverse for pollination and/or fertilization or when the flowers are emasculated. Parthenocarpy is obligate when the fruit is always seedless. In the past, obligate and facultative genetic parthenocarpy was either obtained by alterations of ploidy level or caused by mutations. In recent years, parthenocarpy has also been achieved via transgenesis, as described in the following.
Auxin synthesis within unpollinated ovary has been achieved by expressing the iaaM gene from Pseudomonas syringae under control of the DefH9 (Deficiens Homolog 9) promoter from Antirrhinum majus (Rotino et al. 1997), conferring placenta-ovule-specific expression of tryptophan-2-monooxygenase, known to convert L-tryptophan to indole-3-acetamide (Kosuge et al. 1966). Within plant cells, indole-acetamide is converted by either spontaneous or enzymatic hydrolysis to indole-3-acetic acid (IAA) and ammonia. The DefH9-iaaM construct has been used to induce parthenocarpy in several crop plant species (eggplant, tobacco [Rotino et al. 1997]; tomato [Ficcadenti et al. 1999]; raspberry, strawberry [Mezzetti et al. 2004]; cucumber [Yin et al. 2006]). When cultivated in vitro, wild-type preanthesis tomato flowers need exogenous auxin to develop fruits (Nitsch 1952), whereas DefH9-iaaM preanthesis flower buds develop fruits in medium not supplemented with auxin. Altogether, these data show that enhanced auxin synthesis within the placenta/ovules triggers parthenocarpic fruit development in species belonging to distinct botanical families (e.g., Solanaceae, Rosaceae, and Cucurbitaceae) and with morphologically different fruit types (e.g., tomato, raspberry, and tobacco). Auxin-synthesis parthenocarpy is facultative, because fruits are seedless only under conditions prohibitive for fertilization/pollination.

Parthenocarpy can also be achieved by modifying auxin signaling. Auxin-dependent transcriptional regulation is controlled by the $A u x /$ IAA and AUXIN RESPONSE FACTOR (ARF) gene families (Leyser 2006; Guilfoyle and Hagen 2007). In the absence of auxin, Aux/ IAA proteins bind ARF transcription factors to prevent expression of auxin-response genes. Presence of auxin induces Aux/IAA degradation, thereby allowing the ARFs to activate gene expression. Manipulation of the activity of specific Aux/IAA and ARF family members has now been reported to affect fruit development. In Arabidopsis, parthenocarpy has been obtained by genetic alterations of ARF8 function (Vivian-Smith et al. 2001; Goetz et al. 2006; Goetz et al. 2007). ARF8 is an ovule-specific 
transcription factor that negatively regulates fruit set, and ARF8 gene expression is therefore normally turned off after fertilization (Goetz et al. 2006; Goetz et al. 2007). In tomato, the SlARF7 gene is expressed in placental and ovule tissues and down-regulated soon after pollination. Silencing of the SlARF7 gene leads to parthenocarpic fruit development, showing that SlARF7 functions as a negative regulator of fruit set (de Jong et al. 2009). Similarly, silencing of the IAA9 gene expression also conferred parthenocarpy (Wang et al. 2005). The downregulation of IAA9 mRNAs most likely mimics the degradation of IAA9 protein caused by the increased auxin content of the ovules/ovary that follows fertilization.

In addition to auxin, gibberellin-based approaches have also been used to exploit genetic parthenocarpy in crops. One example is the tomato pat-3/pat-4 line, which was reported to induce parthenocarpic capacity in fruits by increasing the levels of active GAs in the ovary before fertilization (Fos et al. 2001). In a more directed approach, Marti et al. (2007) obtained parthenocarpic tomatoes by RNA silencing of a DELLA gene, providing an additional tool in the box to control this important trait.

The observations in this section show that genetic parthenocarpy can be obtained by manipulating hormone dynamics in various ways in most plant species. Genetic parthenocarpy is advantageous over artificial parthenocarpy because it is environmentally friendlier than spraying hormones in the field and it is uniform and easier to control. Moreover, this area of research provides an illustrative example of how fundamental research that has been invested to understand the biology of hormone activity can be hugely beneficial for crop improvement programs.

\section{ROLE OF AUXIN IN FRUIT DEVELOPMENT AND DEHISCENCE}

\section{Fruit Ripening}

It is well-known that ripening of climacteric fruits such as tomato is promoted by ethylene (Giovannoni 2007), whereas the ripening process in nonclimacteric fruits does not respond to ethylene in the same way (Seymour et al. 1993; Trainotti et al. 2005; Chervin et al. 2008). Observations in both climacteric and nonclimacteric fruits, however, have revealed that decline in auxin levels and in auxin-regulated gene expression correlates with onset of ripening (Given et al. 1988; Cohen 1996; Davies et al. 1997; Catalá et al. 2000), and that ectopically applied auxin delays ripening and represses genes involved in ripening (Vendrell 1985; Manning 1994; Davies et al. 1997; Aharoni et al. 2002). These results suggest that auxin plays an important role in regulating the onset of fruit ripening in these species, possibly by optimizing the capacity of the fruit to ripen.

As described previously the seeds are a major source of auxin, which is transported from the seeds to the rest of the fruit. It is pivotal for the development of viable seeds that seed and fruit maturation is strictly synchronized. Auxin may therefore function as a communicator to ensure such coordination. In the nonclimacteric strawberry, two polygalacturonase $(P G)$ genes were recently identified to play a role in the fast softening process during fruit ripening (Quesada et al. 2009), whereas an enone oxidoreductase gene is responsible for producing the key flavor compound of strawberries (Klein et al. 2007). The activity of these enzymes makes the fruits attractive as food for herbivorous animals, which will aid in dispersal of the seeds. As immature seeds are unlikely to survive a trip through the animal gut, it is crucial that ripening does not take place before seed maturation. Therefore, it makes perfect evolutionary sense that the two PG genes and the enone oxidoreductase gene are all repressed by auxin (Quesada et al. 2009; Klein et al. 2007).

\section{Auxin Minimum and Dehiscence}

After fertilization, Arabidopsis fruits elongate and form a number of specialized tissues including the valves (or seed pod walls), a central replum, and valve margins that form at the valve/replum borders where fruit opening will take place in a process known as pod shatter. 
E. Sundberg and L. Østergaard

This process is the result of a highly coordinated series of events leading to the timely defined dispersal of seeds. The valve margins consist of two distinct cell layers: A pectin-rich separation layer, which will become degraded by secreted pectinases on fruit maturation, and a layer of lignified cells, whose rigidity has been proposed to allow the valves to actively pop off of the fruit in a springlike mechanism to disperse the seeds (Petersen et al. 1996; Degan et al. 2001; Spence et al. 1996; Ogawa et al. 2009).

Setting up the overall patterning process of the Brassicaceae fruit is a prerequisite for proper development, and several of the key genetic factors from Arabidopsis have been isolated in the last decade and their genetic interactions described (Liljegren et al. 2000; Ferrándiz et al. 2000; Liljegren et al. 2004; Roeder et al. 2003; Dinneny et al. 2005). For example, expression of the valve margin identity INDEHISCENT (IND) is restricted to the narrow stripes, where valve margins will form by repression from valve and replum factors.

Previously, Chauvaux et al. (1997) isolated valve and valve margin tissue from $B$. napus fruits and measured the concentrations of IAA throughout development. Interestingly, they found a remarkable correlation between an increase in cell-wall-degrading enzyme activity and a steep decrease in IAA levels in the valve margin tissue immediately before dehiscence. These data suggest that removal of auxin from the valve margin is necessary for fruit opening to take place. It was recently reported that the core genetic network interacts with auxin dynamics to ensure proper fruit patterning (Sorefan et al. 2009). In wild-type fruits, local depletion of auxin in cells of the separation layer is required for fruit opening to take place. In fact, fruit opening could be entirely prevented by expression of an auxin biosynthesis gene, iaaM, at the valve margin under control of the IND gene. It was furthermore found that IND mediates the formation of the auxin minimum by regulating auxin transport in the valve margin: Whereas induction of IND activity led to a dramatic delocalization of PIN auxin transporters to all sides of cells (Fig. 4), a PIN3::PIN3:GFP reporter was found

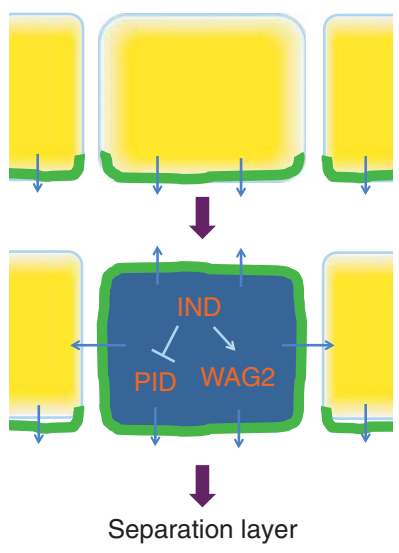

Figure 4. Formation of auxin minimum at the separation layer. IND directly represses PINOID (PID) and activates WAG2 to relocalize PIN auxin efflux carriers. PIN relocalization creates an auxin minimum in the cells, where separation will take place. Green lines indicate PIN localization, whereas cells with DR5::GFP signal are yellow. Small arrows indicate direction of auxin flow.

to be ectopically polarized in the valve margins of ind mutant fruits. Chromatin immuno precipitation revealed that IND mediates changes in PIN polarity by directly and oppositely regulating the expression of the two protein kinase genes PINOID and WAG2 (Fig. 4). The inverse regulation of PID and WAG2 is particularly interesting, as it was recently shown that whereas PID activity leads to polar apical PIN localization (Friml et al. 2004), WAG2 affects PIN polarity differently (Galvan-Ampudia et al., pers. comm.).

The simplicity of obtaining the auxin minimum at the separation layer renders it likely that local depletion of hormones play important roles in other aspects of development. This is perhaps particularly useful for specifying a small number of cells.

\section{CONCLUDING REMARKS}

Although our knowledge of auxin function and spatiotemporal distribution during reproductive development is still far from complete, some basic conclusions can be made from the data reviewed here. Auxin plays a fundamental role in the differentiation process in both male 
and female organs/tissues, and builds instructive gradients during polarity establishment (e.g., gynoecium and gametophyte). Auxin also appears to regulate the timing of events that requires coordination, such as anther dehiscence, pollen maturation, gynoecium development, fertilization, fruit initiation, seed development, and fruit ripening. This is achieved through formation of local concentration maxima and minima, and most likely via interaction with other hormonal pathways. Identifying the mechanisms by which these interactions take place is one of the immediate challenges ahead for reproductive organ development.

\section{ACKNOWLEDGMENTS}

The authors would like to thank the Swedish Research Council and Formas for support to E. Sundberg, and The Biotechnology and Biological Sciences Research Council for support to L. Østergaard.

\section{REFERENCES}

Aharoni A, Keizer LC, Van Den Broeck HC, Blanco-Portales R, Muñoz-Blanco J, Bois G, Smit P, De Vos RC, O’Connell AP. 2002. Novel insight into vascular, stress, and auxin-dependent and -independent gene expression programs in strawberry, a non-climacteric fruit. Plant Physiol 129: 1019-1031

Aloni R, Aloni E, Langhans M, Ullrich CI. 2006. Role of auxin in regulating Arabidopsis flower development. Planta 223: 315-328.

Alvarez J, Smyth D. 1999. AW and SPATULA, two Arabidopsis genes that control carpel development in parallel with AGAMOUS. Development 126: 2377-2386.

Alvarez J, Smyth DR. 2002. CRABS CLAW and SPATULA genes regulate growth and pattern formation during gynoecium development in Arabidopsis thaliana. Int $J$ Plant Sci 163: 17-41.

Alvarez JP, Goldshmidt A, Efroni E, Bowman JL, Eshed Y. 2009. The NGATHA distal organ development genes are essential for style specification in Arabidopsis. Plant Cell 21: $1373-1393$.

Balanza V, Navarrete M, Trigueros M, Ferrandiz C. 2006. Patterning the female side of Arabidopsis: the importance of hormones. J Exp Botany 57: 3457-3469.

Benková E, Michniewichz M, Sauer M, Tiechmann T, Seifertová D, Jürgens G, Friml J. 2003. Local, effluxdependent auxin gradients as a common module for plant organ formation. Cell 115: 591-602.

Bennett SRM, Alvarez J, Bossinger G, Smyth DR. 1995. Morphogenesis in pinoid mutants of Arabidopsis thaliana. Plant J 8: 505-520.
Bowman J. 1994. Arabidopsis. An Atlas of Morphology and Development. Springer-Verlag, New York.

Bowman J, Baum S, Eshed Y, Putterill J, Alvarez J. 1999. Molecular genetics of gynoecium development in Arabidopsis. Curr Topics Develop Biol 45: 155-205.

Castillejo C, Romera-Branchat M, Pelaz S. 2005. A new role of the Arabidopsis SEPALLATA3 gene revealed by its constitutive expression. Plant J 43: 586-596.

Catalá C, Rose JK, Bennett AB. 2000. Auxin-regulated genes encoding cell wall-modifying proteins are expressed during early tomato fruit growth. Plant Physiol 122: 527-534.

Cecchetti V, Altamura MM, Falasca G, Constantino P, Cardarelli M. 2008. Auxin regulates Arabidopsis anther dehiscence, pollen maturation, and filament elongation. Plant Cell 20: 1760-1774.

Cecchetti V, Pomponi M, Altamura MM, Pezzotti M, Marsilio S, D’Angeli S, Tornielli GB, Costantino P, Cardarelli M. 2004. Expression of rolB in tobacco flowers affects the coordinated processes of anther dehiscence and style elongation. Plant J 38: 512-525.

Chauvaux N, Child R, John K, Ulvskov P, Borkhardt B, Prinsen E, Van Onckelen HA. 1997. The role of auxin in cell separation in the dehiscence zone of rapeseed pods. J Exp Botany 48: 1423-1429.

Chen D, Zhao J. 2008. Free IAA in stigmas and styles during pollen germination and pollen tube growth of Nicotiana tabacum. Plant Physiol 134: 202-215.

Cheng Y, Dai X, Zhao Y. 2006. Auxin biosynthesis by the YUCCA flavin monooxygenases controls the formation of floral organs and vascular tissues in Arabidopsis. Genes Dev 20: 1790-1799.

Chervin C, Tira-umphon A, Terrier N, Zouine M, Severac D, Roustan J-P. 2008. Stimulation of the grape berry expansion by ethylene and effects on related gene transcripts, over the ripening phase. Physiol Plant 134: 534-546.

Coen ES. 1992. Flower development. Curr Opin Cell Biol 4: 929-933.

Cohen JD. 1996. In vitro tomato fruit cultures demonstrate a role for indole-3-acetic acid in regulating fruit ripening. J Am Soc Horticultural Sci 121: 520-524.

Crawford BCW, Yanofsky MF. 2008. The formation and function of the female reproductive tract in flowering plants. Curr Biol 18: R972-R978.

Crawford BCW, Ditta G, Yanofsky MF. 2007. The NTT gene is required for transmitting-tract development in carpels of Arabidopsis thaliana. Curr Biol 17: 1101-1108.

Davies C, Boss PK, Robinson SB. 1997. Treatment of crape berries, a nonclimacteric fruit with a synthetic auxin, retards ripening and alters the expression of developmentally regulated genes. Plant Physiol 115: 1155-1161.

Degan FD, Child R, Svendsen I, Ulvskov P. 2001. The cleavable N-terminal domain of plant endopolygalacturonases from clade B may be involved in a regulated secretion mechanism. J Biol Chem 276: 35297-35304.

de Jong M, Wolters-Arts M, Feron R, Mariani C, Vriezen WH. 2009. The Solanum lycopersicum auxin response factor 7 (SIARF7) regulates auxin signaling during tomato fruit set and development. Plant J 57: 160-170. 
Dinneny JR, Weigel D, Yanofsky MF. 2005. A genetic framework for fruit patterning in Arabidopsis thaliana. Development 132: 4687-4696.

Ditta G, Pinyopich A, Robles P, Pelaz S, Yanofsky MF. 2004. The SEP4 gene of Arabidopsis thaliana functions in floral organ and meristem identity. Curr Biol 14: 1935-1940.

Dorcey E, Urbez C, Blazquez MA, Carbonell J, PerezAmador MA. 2009. Fertilization-dependent auxin response in ovules triggers fruit development through the modulation of gibberellin metabolism in Arabidopsis. Plant J 58: 318-332.

Esau K. 1977. Anatomy of Seed Plants. 2nd ed. Wiley, New York.

Feng X-L, Ni W-M, Egle S, Mueller-Roeber B, Xu Z-H, Xue H-W. 2006. Auxin flow in anther filaments is critical for pollen grain development through regulating pollen mitosis. Plant Mol Biol 61: 215-226.

Ferrándiz C, Liljegren SJ, Yanofsky MF. 2000. Negative regulation of the SHATTERPROOF genes by FRUITFULL during Arabidopsis fruit development. Science 289: 436-438.

Ficcadenti N, Sestili S, Pandolfini T, Cirillo C, Rotino GL, Spena A. 1999. Genetic engineering of parthenocarpic fruit development in tomato. Mol Breeding 5: 463-470.

Fos M, Proano K, Nuezc F, García-Martínez JL. 2001. Role of gibberellins in parthenocarpic fruit development induced by the genetic system pat-3/pat-4 in tomato. Physiol Plant 111: 545-550.

Friml J, Yang X, Michniewicz M, Weijers D, Quint A, Tietz O, Benjamins R, Ouwerkerk PBF, Ljung K, Sandberg G, et al. 2004. A PINOID-dependent binary switch in apical-basal PIN polar targeting directs auxin efflux. Science 306: 862-865.

Gillaspy G, Bendavid H, Gruissem W. 1993. Fruits—a developmental perspective. Plant Cell 5: 1439-1451.

Giovannoni JJ. 2007. Fruit ripening mutants yield insights into ripening control. Curr Opin Plant Biol 10: 283-289.

Given NK, Venis MA, Grierson D. 1988. Hormonal regulation of ripening in the strawberry, a non-climacteric fruit. Planta 174: 402-406.

Goethe JWv. 1790. Versuch die Metamorphose der Pflanzen $z u$ Erklaren. C.W. Ettinger, Gotha, Germany.

Goetz M, Hooper LC, Johnson SD, Rodrigues JC, Vivian-Smith A, Koltunow AM. 2007. Expression of aberrant forms of AUXIN RESPONSE FACTOR8 stimulates parthenocarpy in Arabidopsis and tomato. Plant Physiol 145: 351-366.

Goetz M, Vivian-Smith A, Johnson SD, Koltunow AM. 2006. AUXIN RESPONSE FACTOR8 is a negative regulator of fruit initiation in Arabidopsis. Plant Cell 18: 1873-1886.

Goldberg RB, Beals TP, Sanders PM. 1993. Anther development: Basic principles and practical applications. Plant Cell 5: 1217-1229.

Gremski K, Ditta G, Yanofsky MF. 2007. The HECATE genes regulate female reproductive tract development in Arabidopsis thaliana. Development 134: 3593-3601.

Guilfoyle TJ, Hagen G. 2007. Auxin response factors. Curr Opin Plant Biol 10: 453-460.
Gustafson FG. 1936. Inducement of fruit development by growth promoting chemicals. Proc Natl Acad Sci 22: 629-636.

Harberd NP. 2003. Botany. Relieving DELLA restraint. Science 299: 1853-1854.

Heisler M, Atkinson A, Bylstra Y, Walsh R, Smyth D. 2001. SPATULA, a gene that controls development of carpel margin tissues in Arabidopsis encodes a bHLH protein. Development 128: 1089-1098.

Heisler M, Ohno C, Das P, Sieber P, Reddy GV, Long JA, Meyerowitz EM. 2005. Patterns of auxin transport and gene expression during primordium development revealed by live imaging of the Arabidopsis inflorescence meristem. Curr Biol 15: 1899-1911.

Honma T, Goto K. 2001. Complexes of MADS-box proteins are sufficient to convert leaves into floral organs. Nature 409: 525-529.

Ishiguro S, Kawai-Oda A, Ueda J, Nishida I, Okada K. 2001. The DEFECTIVE IN ANTHER DEHISCHENCE gene encodes a novel phospholipase Al catalyzing the initial step of jasmonic acid biosynthesis, which synchronizes pollen maturation, anther dehiscence, and flower opening in Arabidopsis. Plant Cell 13: 2191-2209.

Kaufmann K, Muin JM, Jauregui R, Airoldi CA, Smaczniak C, Krajewski P, Angenent GC. 2009. Target genes of the MADS transcription factor SEPALLATA3: Integration of developmental and hormonal pathways in the Arabidopsis flower. PLOS Biol 7: e1000090.

King GN. 1947. Artificial parthenocarpy in Lycopersicum esculentum; tissue development. Plant Physiol 22: 572-581.

Klein D, Fink B, Arold B, Eisenreich W, Schwab W. 2007. Functional characterization of enone oxidoreductases from strawberry and tomato fruit. J Agricult Food Chem 55: 6705-6711.

Koshioka M, Nishijima T, Yamazaki H, Liu Y, Nonaka M, Mander LN. 1994. Analysis of gibberellins in growing fruits of Lycopersicon esculentum after pollination or treatment with 4- chlorophenoxyacetic acid. J Horticul Sci 69: 171-179.

Kosuge T, Heskett MG, Wilson EE. 1966. Microbial synthesis and degradation of indole-3-acetic acid. J Biol Chem 241 3738-3744.

Kuusk S, Sohlberg JJ, Eklund DM, Sundberg E. 2006. Functionally redundant $\mathrm{SHI}$ family genes regulate Arabidopsis gynoecium development in a dose-dependent manner. Plant J 47: 99-111.

Kuusk S, Sohlberg JJ, Fridborg I, Long J, Sundberg E. 2002. STY1 and STY2 promote the formation of apical tissues during Arabidopsis gynoecium development. Development 129: 4707-4717.

Lennon K, Roy S, Hepler P, Lord E. 1998. The structure of the transmitting tissue of Arabidopsis thaliana (L.) and the path of pollen tube growth. Sex Plant Reprod 11: 49-59.

Leyser O. 2006. Dynamic integration of auxin transport and signaling. Curr Biol 16: R424-433.

Li M, Xu W, Yang W, Kong Z, Xue Y. 2007. Genome-wide gene expression profiling reveals conserved and novel molecular functions of the stigma in rice. Plant Physiol 144: $1797-1812$.

Liljegren SJ, Ditta GS, Eshed Y, Savidge B, Bowman JL, Yanofsky MF. 2000. SHATTERPROOF MADS-box 
genes control seed dispersal in Arabidopsis. Nature 404: 766-770.

Liljegren SJ, Roeder AH, Kempin SA, Gremski K, Østergaard L, Guimil S, Reyes DK, Yanofsky MF. 2004. Control of fruit patterning in Arabidopsis by INDEHISCENT. Cell 116: $843-853$.

Ma H. 2005. Molecular genetic analyses of microsporogenesis and microgametogenesis in flowering plants. Annu. Rev. Plant Biol 56: 393-434.

Manning K. 1994. Changes in gene expression during fruit ripening and their regulation by auxin. Planta 194: $62-68$.

Marti C, Orzaez D, Ellul P, Moreno V, Carbonell J, Granell A. 2007. Silencing of DELLA induces facultative parthenocarpy in tomato fruits. Plant J 52: 865-876.

McCormick S. 2004. Control of male gametophyte. Plant Cell 16: S142-S153.

Mezzetti B, Landi L, Pandolfini T, Spena A. 2004. The defH9-iaaM auxin-synthesizing gene increases plant fecundity and fruit production in strawberry and raspberry. BMC Biotechnol 4: 1-4.

Nagpal P, Ellis CM, Weber H, Ploense SE, Barkawi LS, Guilfoyle TJ, Hagen G, Alonso JM, Cohen JD, Farmer EE, et al. 2005. Auxin response factors ARF6 and ARF8 promote jasmonic acid production and flower maturation. Development 132: 4107-4118.

Nemhauser JL, Feldman LJ, Zambryski PC. 2000. Auxin and ETTIN in Arabidopsis gynoecium morphogenesis. Development 127: 3877-3888.

Nitsch JP. 1952. Plant hormones in the development of fruit. Quart Rev Biol 27: 33-57.

Noh B, Murphy AS, Spalding EP. 2001. Multidrug resistance-like genes of Arabidopsis required for auxin transport and auxin mediated development. Plant Cell 13: 2441-2454.

Ogawa M, Kay P, Wilson S, Swain SM. 2009. ARABIDOPSIS DEHISCENCE ZONE POLYGALACTURONASE (ADPG1), ADPG2, and QUARTET2 are polygalacturonases required for cell separation during reproductive development in Arabidopsis. Plant Cell 21: 216-233.

Okada K, Ueda J, Komaki MK, Bell CJ, Shimura Y. 1991. Requirement of the auxin polar transport system in early stages of Arabidopsis floral bud formation. Plant Cell 3: 677-684.

Østergaard L. 2009. Don't 'leaf' now. The making of a fruit. Curr Opin Plant Biol 12: 36-41.

Ozga JA, van Huizen R, Reinecke DM. 2002. Hormone and seed-specific regulation of pea fruit growth. Plant Physiol 128: $1379-1389$.

Ozga JA, Yu J, Reinecke DM. 2003. Pollination-, development-, and auxin-specific regulation of gibberellin 3betahydroxylase gene expression in pea fruit and seeds. Plant Physiol 131: 1137-1146.

Ozga JA, Reinecke DM, Ayele BT, Ngo P, Nadeau C, Wickramarathna AD. 2009. Regulation of GA biosynthesis and catabolism in pea fruit. Plant Physiol 150: 448-462.

Pagnussat GC, Alandete-Saez M, Bowman JL, Sundaresan V. 2009. Auxin-dependent patterning and gamete specification in the Arabidopsis female gametophyte. Science 324: 1684-1689.
Pacini E, Franchi GG, Hesse M. 1985. The tapetum: Its form, function and possible phylogeny in embryophyta. Plant System Evol 149: 155-185.

Pekker I, Alvarez JP, Eshed Y. 2005. Auxin response factors mediate Arabidopsis organ asymmetry via modulation of KANADI activity. Plant Cell 17: 2899-2910.

Pelaz S, Tapia-Lopez R, Alvarez-Buylla ER, Yanofsky MF. 2001. Conversion of leaves into petals in Arabidopsis. Curr Biol 15: 1998-2006.

Peng J, Carol P, Richards DE, King KE, Cowling RJ, Murphy GP, Harberd NP. 1997. The Arabidopsis GAI gene defines a signaling pathway that negatively regulates gibberellin responses. Genes Develop 11: 3194-3205.

Petersen M, Sander L, Child R, van Onckelen H, Ulvskov P, Borkhardt B. 1996. Isolation and characterisation of a pod dehiscence zone-specific polygalacturonase from Brassica napus. Plant Mol Biol 31: 517-527.

Przemeck GKH, Mattsson J, Hardtke CS, Sung ZR, Berleth T. 1996. Studies on the role of the Arabidopsis gene MONOPTEROS in vascular development and plant cell axialization. Planta 200: 229-237.

Quesada MA, Blanco-Portales R, Posé S, García-Gago JA, Jiménez-Bermúdez S, Muñoz-Serrano A, Caballero JL, Pliego-Alfaro F, Mercado JA, Muñoz-Blanco J. 2009. Antisense down-regulation of the FaPG1 gene reveals an unexpected central role for polygalacturonase in strawberry fruit softening. Plant Physiol 150: 1022-1032.

Reinhardt D, Mandel T, Kuhlemeier C. 2000. Auxin regulates the initiation and radial position of plant lateral organs. Plant Cell 12: 507-518.

Reinhardt D, Pesce ER, Steiger P, Mandel T, Baltensperger K, Bennett M, Traas J, Friml J, Khulemeier C. 2003. Regulation of phyllotaxix by polar auxin transport. Nature 426: $255-260$.

Roeder AHK, Yanofsky MF. 2005. Fruit development in Arabidopsis. The Arabidopsis Book 52: 1-50.

Roeder AH, Ferrándiz C, Yanofsky MF. 2003. The role of the REPLUMLESS homeodomain protein in patterning the Arabidopsis fruit. Curr Biol 13: 1630-1635.

Rotino GL, Perri E, Zottini M, Sommer H, Spena A. 1997. Genetic engineering of parthenocarpic plants. Nat Biotechnol 15: 1398-1401.

Ru P, Xu L, Ma H, Huang H. 2006. Plant fertility defects induced by the enhanced expression of microRNA167. Cell Res 16: 457-465.

Sanders PM, Lee PY, Biesgen C, Boone JD, Beals TP, Weiler EW, Goldberg RB. 2000. The Arabidopsis DELAYED DEHISCENCE1 gene encodes an enzyme in the jasmonic acid synthesis pathway. Plant Cell 12: 1041-1061.

Santner A, Estelle M. 2009. Recent advances and emerging trends in plant hormone signaling. Nature 459: 1071-1078.

Sastry KKS, Muir RM. 1963. Gibberellin: Effect on diffusible auxin in fruit development. Science 140: 494-495.

Sessions RA, Zambryski PC. 1995. Arabidopsis gynoecium structure in the wild type and in ettin mutants. Development 121: 1519-1532.

Sessions A, Nemhauser JL, McCall A, Roe JL, Feldman KA, Zambryski PC. 1997. ETTIN patterns the Arabidopsis floral meristem and reproductive organs. Development 124: $4481-4491$. 


\section{E. Sundberg and L. Østergaard}

Seymour GB, Fray RG, Hill P, Tucker GA. 1993. Down-regulation of two non-homologous endogenous tomato genes with a single chimaeric sense gene construct. Plant Mol Biol 23: 1-9.

Silverstone AL, Ciampaglio CN, Sun T-P. 1998. The Arabidopsis RGA gene encodes a transcriptional regulator repressing the gibberellin signal transduction pathway. Plant Cell 10: 155-169.

Skinner DJ, Gasser CS. 2009. Expression-based discovery of candidate ovule development regulators through transcriptional profiling of ovule mutants. BMC Plant Biol 9: 29.

Sohlberg JJ, Myrenås M, Kuusk S, Lagercrantz U, Kowalczyk M, Sandberg G, Sundberg E. 2006. STY1 regulates auxin homeostasis and affects apical-basal patterning of the Arabidopsis gynoecium. Plant J 47: 112-123.

Sorefan K, Girin T, Liljegren SJ, Ljung K, Robles P, Galván-Ampudia CS, Offringa R, Friml J, Yanofsky MF, Østergaard L. 2009. A regulated auxin minimum is required for seed dispersal in Arabidopsis. Nature 459: 583-586.

Spence J, Vercher Y, Gates P, Harris N. 1996. 'Pod shatter' in Arabidopsis thaliana, Brassica napus and B. juncea. J Microsc 181: 195-203.

Srinivasan A, Morgan DG. 1996. Growth and development of the pod wall in spring rape (Brassica napus) as related to the presence of seeds and exogenous phytohormones. J Agricult Sci 127: 487-500.

Sundberg E, Ferrandíz C. 2009. Gynoecium patterning in Arabidopsis: A basic plan behind a complex structure. In: Fruit development and seed dispersal. Annual Plant Reviews ( L. Østergaard, ed.) 38: 35-69.

Tobena-Santamaria R, Bliek M, Ljung K, Sandberg G, Mol JN, Souer E, Koes R. 2002. FLOOZY of petunia is a flavin mono-oxygenase-like protein required for the specification of leaf and flower architecture. Genes Dev 16: $753-763$.

Trainotti L, Pavanello A, Casadoro G. 2005. Different ethylene receptors show an increased expression during the ripening of strawberries: Does such an increment imply a role for ethylene in the ripening of these nonclimacteric fruits? J Exp Bot 56: 2037-2046.

Trigueros M, Navarrete-Gómez M, Sato S, Christensen SK, Pelaz S, Weigel D, Yanofsky MF, Ferrándiz C. 2009.
The NGATHA genes direct style development in the Arabidopsis gynoecium. Plant Cell 21: 1394-1409.

Vendrell M. 1985. Dual effect of 2,4-D on ethylene production and ripening of tomato fruit tissue. Physiol Plant 64: 559-563.

Vernoux T, Kronenberger J, Grandjean O, Laufs P, Traas J. 2000. PIN-FORMED1 regulates cell fate at the periphery of the shoot apical meristem. Development 127: 51575165.

Vivian-Smith A, Koltunow AM. 1999. Genetic analysis of growth-regulator-induced parthenocarpy in Arabidopsis. Plant Physiol 121: 437-452.

Vivian-Smith A, Luo M, Chaudhury A, Koltunow AM. 2001. Fruit development is actively restricted in the absence of fertilization in Arabidopsis. Development 128: $2321-2331$.

Wang H, Jones B, Li Z, Frasse P, Delalande C, Regad F, Chaabouni S, Latche A, Pech J, Bouzayen M. 2005. The tomato Aux/IAA transcription factor IAA9 is involved in fruit development and leaf morphogenesis. Plant Cell 17: 2676-2692.

Wang H, Jones B, Li Wang H, Wu HM, Cheung AY. 1996. Pollination induces mRNA poly(A) tail-shortening and cell deterioration in flower transmitting tissue. Plant J 9: 715-727.

Weigel D, Meyerowitz EM. 1994. The ABCs of floral homeotic genes. Cell 78: 203-209.

Wilson ZA, Zhang D-B. 2009. From Arabidopsis to rice: Pathways in pollen development. J Exp Bot 60: 1479-1492.

Wittwer SH, Bukovac MJ, Sell HM, Weller LE. 1957. Some effects of gibberellin on flowering and fruit setting. Plant Physiol 32: 39-41.

Wu M-F, Tian Q, Reed JW. 2006. Arabidopsis microRNA167 controls patterns of ARF6 and ARF8 expression, and regulates both female and male reproduction. Development 133: 4211-4218.

Yang H, Wei Z, Xu Z. 1997. Effects of specific expression of iaaL in tobacco tapetum on pollen embryogenesis. Sci China C Life Sci 40: 384-391.

Yin ZM, Malinowski R, Ziolkowska A, Sommer H, Plader W, Malepszy S. 2006. The DefH9-iaaM-containing construct efficiently induces parthenocarpy in cucumber. Cell Mol Biol Lett 11: 279-290. 


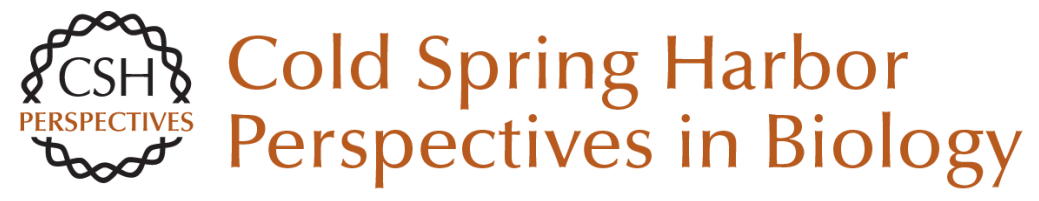

\section{Distinct and Dynamic Auxin Activities During Reproductive Development}

Eva Sundberg and Lars Østergaard

Cold Spring Harb Perspect Biol 2009; doi: 10.1101/cshperspect.a001628 originally published online October 14, 2009

\section{Subject Collection Auxin Signaling}

\section{Fourteen Stations of Auxin} Jirí Friml

Computational Models of Auxin-Driven Patterning in Shoots

Mikolaj Cieslak, Andrew Owens and Przemyslaw Prusinkiewicz

Auxin Transporters--A Biochemical View Ulrich Z. Hammes, Angus S. Murphy and Claus Schwechheimer

Structural Aspects of Auxin Signaling Nicholas Morffy and Lucia C. Strader

The Story of Auxin-Binding Protein 1 (ABP1) Richard Napier

Noncanonical Auxin Signaling Heather Marie McLaughlin, Aaron Chun Hou Ang and Lars Østergaard

Casting the Net--Connecting Auxin Signaling to the Plant Genome

Yanfei Ma, Sebastian Wolf and Jan U. Lohmann

Auxin Plays Multiple Roles during Plant-Pathogen Interactions

Barbara N. Kunkel and Joshua M.B. Johnson
Auxin in Root Development

Suruchi Roychoudhry and Stefan Kepinski

Modeling Auxin Signaling in Roots: Auxin

Computations

Jaap Rutten, Thea van den Berg and Kirsten ten Tusscher

The Systems and Synthetic Biology of Auxin $R$. Clay Wright, Britney L. Moss and Jennifer $L$. Nemhauser

Auxin Does the SAMba: Auxin Signaling in the Shoot Apical Meristem Markéta Pernisová and Teva Vernoux

Chemical Biology in Auxin Research Ken-ichiro Hayashi

Uncovering How Auxin Optimizes Root Systems

Architecture in Response to Environmental

Stresses

Nicola Leftley, Jason Banda, Bipin Pandey, et al.

Auxin Interactions with Other Hormones in Plant

Development

Serina M. Mazzoni-Putman, Javier Brumos, Chengsong Zhao, et al.

No Time for Transcription--Rapid Auxin

Responses in Plants

Shiv Mani Dubey, Nelson B.C. Serre, Denisa Oulehlová, et al.

For additional articles in this collection, see http://cshperspectives.cshlp.org/cgi/collection/

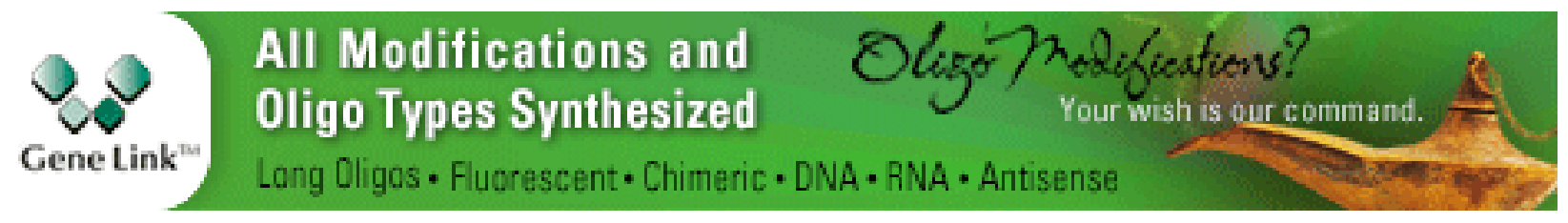

Copyright @ 2009 Cold Spring Harbor Laboratory Press; all rights reserved 
For additional articles in this collection, see http://cshperspectives.cshlp.org/cgi/collection/

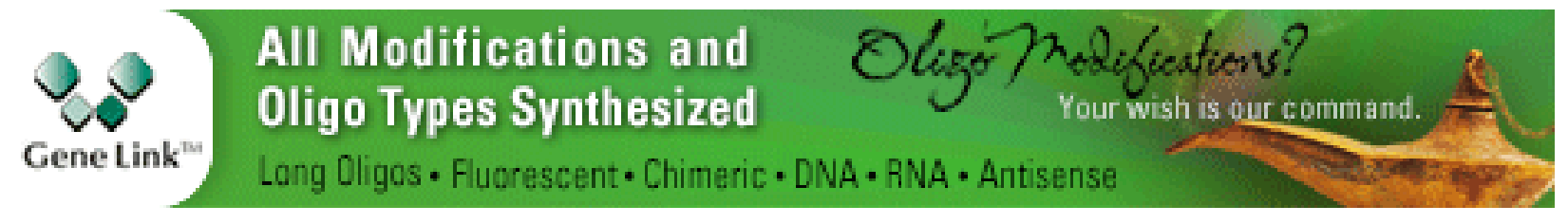

Copyright @ 2009 Cold Spring Harbor Laboratory Press; all rights reserved 